test tube inverted over another, the latter containing the culture medium and being longer and slightly narrower than the former; the covering tube may be 4 inches by $\frac{7}{8}$ inch and the inner tube 6 inches by $\frac{3}{4}$ inch. The outer tube is kept in position by the help of a spring attached to a ring which surrounds and fits on the lower tube. The arrangement is shown in the illustration. The spring is strong enough to prevent the upper tube slipping off from the lower one in case the tubes are lifted up from a stand by holding

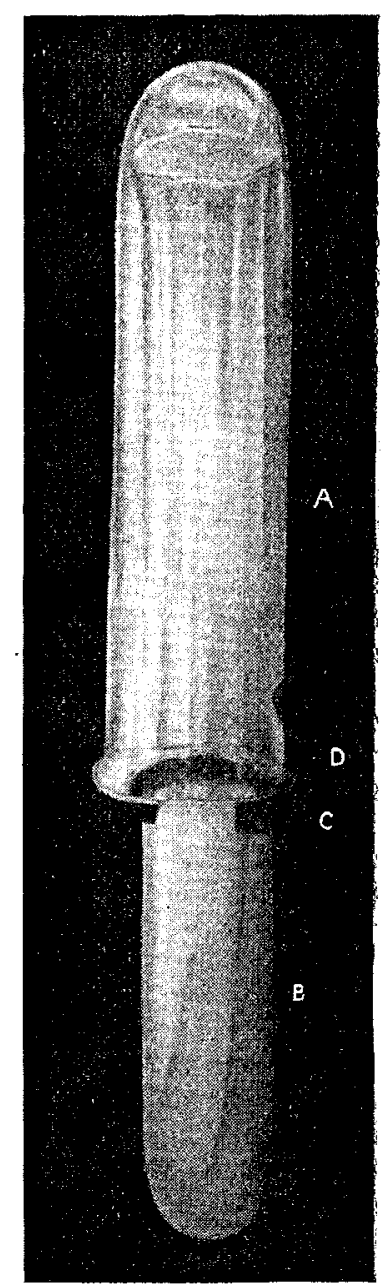

A, The outer covering test tube. $B$, The inner tube. $C$, The ring to which the spring $D$ is attached.

the upper one; but it will allow the upper tube being removed by a slight pull when required for introduction of needles, \&c, for the purposes of inoculation. When culture tubes provided with this mechanism are to be cleaned the ring surrounding the lower tube can be easily slipped off and the tubes can be cleaned in the ordinary way by chemicals, \&c.

The following procedure should be adopted in filling these tubes with culture media and for sterilising them. Both sets of tubes are at the outset to be thoroughly sterilised and then they are to be arranged one over the other as described before and the ring slipped into the lower tube and the spring adjusted so that it touches the rim of the upper tube. as shown in the illustration. They are sterilised in the hot-air steriliner. They are then ready fờ receiving the culture medium with which they can be filled by taking off the upper tube which can be more easily managed than removing the tightly packed cotton plug of an ordinary tube. Subsequent procedures of sterilisation, \&c., are managed in the same way as with an ordinary tube. In inoculating a tube the upper one is removed while holding both tubes in an inclined position, as is done with an ordinary test tube, and then inoculating the culture medium and subsequently replacing the upper tube. There is no necessity for scorching the ends of the tubes as in done in case of the cotton-plugged tubes, as there is no chance of contamination of the ends, as they are not touched by the fingers, the tubes being held by the other ends. Accordingly it saves a good deal of time and worry when one has to deal with a large number of tubes. The tubes of this kind have been in use in the bacteriological laboratory, Calcutta
Medical College, along with the ordinary tubes for over six months and have hitherto given uniformly satisfactory results. They have not been contaminated except in a few cases where in taking a tube from a stand the upper tube has slipped off from the lower tube owing to the spring not being sufficiently strong to keep the tubes in position and the tubes were subsequently found to be contaminated. In one instance some ants got inside the tube containing the culture medium and contaminated it. They got into the tube through the opening between the two not properly fitting tubes-an ordinary tube being used as the covering tube, allowing a large amount of space between the two. Even with these there have been very few contaminations.

The advantages of this method of preparing culture tubes over the ordinary method are the following. 1. In moist hot climates the cotton plugs get easily grown with fungi which contaminate the culture media contained inside the tubes, but in this method there is no chance of this happening. 2 . In filling tubes with culture media in this method the removal and replacing of the upper covering tube are much more easily managed than the removal and putting back of a cotton plug of an ordinary tube. 3 . In the same way in inoculating tubes they can be managed much more easily than the ordinary tubes. 4. Cotton fibres adhering to the mouths of the tubes get soiled with bacilli from the platinum wire introduced for the purpose of inoculating and these fibres in their turn contaminate the glass handle of the platinum wire and consequently become a source of danger to the inoculator, whereas in the other case there is no chance of this. happening. 5. The inconvenience experienced on account. of burning of cotton plugs is obviated. 6 . In the ordinary method the cotton plugs once used have to be thrown away and to be renewed each time so that there is a heavy item of expenditure on this account, whereas in the other method every part of the apparatus can be used over and over again.

The only disadvantage is in the case of tubes packed for sending by post when there is a risk of foreign particles. falling in between the tubes while they are inverted.

Calcutta.

\section{NOTES ON TWO CASES OF PAROXYSMAL* TACHYCARDIA.}

BY R. O. MOON, M.D. OXON., M.R C.P. LOND.,

PHYSICTAN TO THE WESTERN GFNERAL DISPENSARY, MARYLEBONEROAD LONDON, N.W ; PHYSICIAN TO THE NATIONAL HOSPITAL FOR DISEASES OF THE HEART, SUHO SQUARE. W ; AND PHYSICIAN TO "UT-PATIENTS AT THE ROYAI WATERLOO HOSPITAI FOR CHILDREN AND WOMEN, WATERLOO-ROAD, S.E.

Two cases of paroxysmal tachycardia have recently come under my notice and as it is not a common condition they seem worth recording.

CASE 1.-A girl, aged 20 years, of Semitic origin, by occupation a waitress, came to the out-patients' department of the National Hospital for Diseases of the Heart for periodical attacks of palpitation of the heart occurring on an average about every three weeks but bearing no relation to the catamenia. As a rule the attack came on suddenly, though at times for a few hours beforehand her voice became weak, almost passing into a condition of aphonia. The attack generally lasted from 24 to 36 hours and then stopped abruptiy, and she experienced a sensation as if the heart haō "jerked itself into the right place." There was a dull pain during the attack over the shoulders and in the left side. In the intervals she was fairly well. The attacks began five years ago and there was nothing definite to account for the first attack. When I first saw ber the pulse was very rapid-210 while lying down, 224 after walking, but quite regular and of moderate tension. The cardiac impulse was forcible but the position of the apex beat and the limits of cardiac dulness were normal and there were no murmurs. The most striking feature, however, was that though somewhat distrossed she did not seem very ill in spite of the great rapidity of the pulse, and the breathing was fairly quiet. Being quite well in the intervals and able to do her work, she cou'd not be persuaded to come into the hospital where

${ }^{*}$ In spite of Professor Clifford Allbutt's strictures on this nomen clature the term "tachycardia" in current medical literature appears to connote a continuolusly rapid cardiac action, and therefore the epithet "paroxysmal" as applied to these cases is not otiose. 
she could have been under observation. In September, 1906, she had a very severe attack lasting four and a balf duys, during which I was able to see her twice. The paroxysm had seized her suddenly in the night while at rest, but she was able to continue at work the following day ; after that, however, she bad to take to her bed. When I saw her she was lying on her left side, very much exhausted and sweating considerably. She complained of pain in the upper part of the chestand down the left arm, but it was not acute. The pulse was 180 , but in other respects the heart was normal. When seen two days later she looked extremely ill and there was an ashen pallor of the face; she did not complain of pain but was feeling very greatly exhausted. The pulse was uncountable at the wrist, being 260 with the stethoscope, and there were signs of dilatation of the heart. The next day the pulse dropped to 90 and she was soon out of the attack, but she felt weak and battered for from three to four days, and then resumed her work. This was by far the longest attack she had ever had and it has not been repeated. During the attack digitalis proved of no avail; she seemed to experience relief by having cold water poured over the wrists. Since she has been under out-patient treatment the attacks have certainly been less frequent. The drugs which have seemed most useful are bromide of potassium and hyoscyamus.

CASE 2.-The patient was a young man, aged 23 years. When 18 years old he was said to have had "muscular rheumatism" and was in bed for ten weeks, so presumably the valves of his heart were damaged at that time. A year later he had an attack of influenza, followed by pleurisy and pneumonia. About two and a half jears ago he began to have attacks of palpita tion of the heart, which at first occurred about once a month, but for the last one and a half years he had har on an average two a week and had never been for more than a fortnight without an attack. The first attack seemed to come on after rather a long bicycle ride, but he had never been able to discover any other cause for the ensuing attacks. In appearance he was a small, rather wirylooking fellow, but pale-faced with an anxious expression and dilated pupils. On examination bis heart showed some hypertrophy of the right ventricle; there were a presystolic thrill and murmur, and the liver was two inches below the costal margin. As a rule the pulse was rather slow, varying from 60 to 66 , full, and of moderate tension The blood pressure was 120 (taken by Martin's manometer) The attack of palpitation came on suddenly and the pulserate ran up to 240 , becoming uncountable at the wrists but the beats were regular and the ordinary condition of his heart was unchanged; he sometimes had a feeling of impending death but there was no acute pain; he usually sweated profusely. This condition lasted from 20 to 30 hours and then came to an end as suddenly as it began. Like Case 1, he said it felt as though the heart had jerked itself into the right place again. He generally felt very drowsy after an attack. Often the attacks began at night, when he was lying quietly in bed, and these were usually the worst. At times he felt particularly well for a couple of days prior to the attack. Though the attacks certainly caused bim more general distress than Case 1 , he was yet able to get about while they lasted and had indeed come up to the hospital with an attack on him. He came into the hospital for two months, but the rest in bed did not seem to do him much good and treatment during the attacks was not satisfactory, although they were less prolonged than when at home. Among drugs erythrol tetranitrate seemed to give him most relief and occasionally digitalis cut short an attack; neither drinking hot coffee nor ice to the præcordium nor a blister to the spine appeared to be of the smallest use. On several occasions, however, he found that vomiting relieved him, so acting on this he was given an emetic and nearly always the attack ceased after iue had vomited. This method of treatment certainly had a depressing effect upon him in the intervals and is not to be recommended. From pressure on the vagi in the neck, which had been suggested by some, I obtained no satisfactory result. Rosenfeld claims to have cured four cases by making the patient press bis elbows into the sides, and at the same time making pressure on the aodomen. This certainly afforded some temporary relief in this case, the patient saying that during the attack the principal discomfort was the feeling of shaking in the abdomen, which extended down to the thighs, and this was relieved by the pressure.

There is a good deal of literature on this subject, but it can hardly be described as illuminating, either as regards cause or pathology. There is some agreement in regarding over-work, either bodily or mental, or an injury as the exciting cause, but this did not appear in the above cases. As to pathology, it would seem natural to suggest a lesion of the vagus, but l'rofessor Olifford Allbutt has pointed out that this would only raise the pulse to 140 and certainly would not account for the great acceleration of the rate described above. Others have regarded it as a bulbar spinal neurosis, while S. West ${ }^{1}$ considers the myocardium to be the seat of the lesion. Gibson ${ }^{2}$ has pointed out the analcgy between paroxysmal tachycardia and delirinm cordis, which would accord with the idea that the seat of the lesion is in the myocardium. Such post-mortem examinations as have occurred show no trace of any nerve lesion, whereas fatty degeneration of the heart muscle has been found once, chronic interstitial myocarditis twice, and cardiac dilatation three times. Hoffman ${ }^{3}$ states that in 13 necropsies myocarditic changes were present in all, and these were usually recent. He does not, however, believe that the myocardial condition was responsible for the disease. On the contrary, he is of opinion that the essential lesion must be located in the central nervous system and considers the paroxysms similar in nature to an epileptiform attack; certainly there is much in these attacks to suggest something in the nature of Liveing's " nerve storms" or of the paroxysmal neuroses.

Some cases present a great variety in the paroxysms which at times last only a few hours, at others for several weeks. Hochhaus ${ }^{4}$ quotes a case in which there was cdema of the whole body, bronchitis, and anuria, which all vanished rapidly when the heart returned to its normal state. Post mortem nothing definite was found. According to Herringham ${ }^{5}$ if the attack lasts more than five days secondary symptoms-e.g., bronchitis and pulmonary odema - will probably appear. Bouveret, ${ }^{6}$ who was the first to give any complete account of paroxysmal tachycardia, does not include cases with organic cardiac lesions, but this is surely an unnecessary refinement, for paroxysmal tachycardia has clearly no essential connexion with valvular disease and, therefore, although Case 2 was suffering from mitral stenosis, it seems quite reasonable to regard it as an example of paroxysmal tachycardia. The prognosis is certainly not good, for after 30 years of age a patient is never safe from death. In the intervals, however, patients are able to resume their ordinary avocations and indeed to do fairly hard work without experiencing either palpitation or dyspncea. According to Bouveret, the acute dilatation of the cardiac cavities which characterises a prolonged attack (accès de longue durée) does not pass into a chronic dilatation which can be appreciated in the intervals of the paroxysms. Nevertheless, the attacks tend to recur with greater frequency, gradually becoming longer, more intense, and more grave till the final syncope.

Green-street, Park-lane, W.

\section{BLOOD PRESSURE IN FEVERS.}

BY JAMES DAVIDSON, M.D. EDIN., \&c., MEDICAL OFFICER, LONDUN MISSIONARY SOCTETY HOSPITAI, NEYOOR, TRAVANCORE, SOUTH INDIA.

WITH the advent of many improved forms of apparatus for the accurate estimation of blood pressure, sphygmometry has now become a valuable aid to diagnosis in many forms of disease. When one begins to study the pulse and the circulation in fevers, the changes which are attributable to the fever itself must be carefully distinguished from those which are merely secondary to pyrexia. 'T'he increase in the pulse-rate which occurs is -in the first case, at any ratesimply due to the increase in temperature of the blood. Liebermaster has shown that in man there is an increase of about 14 beats per minute for each degree Centigrade-or eight beats for each degree Fahrenheit--of increased temverature. This phenomenon is particularly well illustrated in the early stages of many cases of enteric fever. Increase in the pulse-rate beyond this physiological ratio must be

1 Transactions of the Medical Society of London, vol. xiii., p. 318. Diseases of the Heart and Aorta, p. 804.

3 Deutsches Archiv fur Kliniscbe Medicin, Band Ixx viii., S. 39. Ibid., Band li. S. 17

Edinburgh Medical Journal, 1897.

¿ Revue de Médecine, Paris, 1889, tome ix., p. 753 